\title{
Seasonal variation of non-shivering thermogenesis (NST) during mild cold exposure
}

\author{
Takayuki Nishimura ${ }^{1 *}$, Midori Motoi ${ }^{2}$, Yuka Egashira ${ }^{2}$, Damee Choi $^{2}$, Kiyoshi Aoyagi ${ }^{1}$ and Shigeki Watanuki
}

\begin{abstract}
Background: The physiological function of non-shivering thermogenesis (NST) has been investigated in recent years, and some studies have discussed the importance of NST with respect to human cold adaptation. The present study aimed to clarify individual and seasonal variations in NST that occurred as a result of mild cold exposure.

Methods: Seventeen male university students participated in the present study during summer and winter. The climate chamber used was programmed so that ambient temperature dropped from $28^{\circ} \mathrm{C}$ to $16^{\circ} \mathrm{C}$ over an 80 -min period. Physiological parameters of test subjects were recorded during the experiments.

Results: Increases in oxygen intake $\left(\mathrm{VO}_{2}\right)$ during cold exposure were significantly greater without shivering in winter than they were in summer. Respiratory exchange ratio (RER) was significantly lower during thermoneutral baseline and cold exposure in winter than it was during the same periods in summer. In addition, there was a significant negative correlation between $\Delta \mathrm{VO}_{2}$ and $\triangle \mathrm{RER}$.

Conclusions: Increase of $\mathrm{VO}_{2}$ without shivering indicated increase of NST, and decrease of RER depends on the metabolization of fat in winter. These results suggested that NST activity was activated by seasonal acclimatization, and individual variation of NST depends on individual variation of fat metabolism.
\end{abstract}

Keywords: Non-shivering thermogenesis, Oxygen intake, Cold exposure, Seasonal acclimatization

\section{Background}

Adaptation to cold environments played an important role in the survival of Homo sapiens during the last ice age, and variations with respect to cold adaptation are reflected in human phenotypes today [1,2]. When humans are exposed to cold environments, vasoconstriction occurs to regulate heat loss; however, the degree to which the thermal environment can be adjusted by vasoconstriction is small, and thermogenesis is required to maintain optimal body temperature.

Thermogenesis can be divided into shivering thermogenesis (ST) and non-shivering thermogenesis (NST); the former is considered to be the main form of thermogenesis in humans. In laboratory studies, we previously demonstrated seasonal variation in the lower respiratory exchange ratio (RER) with shivering during acute cold exposure $\left(10^{\circ} \mathrm{C}\right)$ in winter [3]. RER is defined as the ratio of carbon dioxide output $\left(\mathrm{VCO}_{2}\right)$ to oxygen intake $\left(\mathrm{VO}_{2}\right)$.

\footnotetext{
* Correspondence: takayuki-n@nagasaki-u.ac.jp

${ }^{1}$ Department of Public Health, Nagasaki University Graduate School of Biomedical Sciences, 1-12-4 Sakamoto, Nagasaki 852-8523, Japan Full list of author information is available at the end of the article
}

High RER values indicate glucose metabolism, while low RER values indicate fat metabolism. Mäkinen et al. [4] reported that some individuals exhibited increased $\mathrm{VO}_{2}$ without shivering during a 24-h period of cold exposure $\left(10^{\circ} \mathrm{C}\right)$ in winter. In addition, Vybúral [5] reported the importance of hormonal effects on NST in winter swimmers. These results suggested that seasonal acclimatization of thermogenesis occurred by including NST.

To better understand energy expenditure during cold exposure, it is necessary to examine ST and NST separately and to elucidate seasonal variation in NST. The present study aimed to elucidate seasonal variation of NST through mild cold exposure. It was hypothesized that energy expenditure would increase without shivering in winter.

\section{Methods \\ Participants}

Participants in the study comprised 17 university students (20 to 24 years old) with no known medical problems. All were Japanese men and were non-athletes. After having 
the experimental conditions fully explained to them, participants gave written consent to their participation. Table 1 shows the morphological characteristics of the participants during each season. Body mass index (BMI) was calculated as follows: body mass $(\mathrm{kg}) /$ height $^{2}\left(\mathrm{~m}^{2}\right)$. Body surface area (BSA) was calculated using Kurazumi's formula [6]. Body fat was calculated by Brozek's formula [7].

Experiments were approved by the Ethics Committee of the Graduate School of Design, Kyushu University.

\section{Experimental procedure}

Experiments were conducted in summer (August to September) and winter (February to March) in Fukuoka, Japan. Average temperature during experiment in Fukuoka was $28.3^{\circ} \mathrm{C}$ in summer and $8.5^{\circ} \mathrm{C}$ in winter (Figure 1) (Japan Meteorological Agency). Participants abstained from food and drink for at least $2 \mathrm{~h}$ prior to experimentation.

Prior to experimentation, sensors were attached to each participant at an ambient temperature of $28^{\circ} \mathrm{C}$. Participants then rested quietly for a period of $20 \mathrm{~min}$ in a climate chamber prior to commencement of cold exposure. The climate chamber used was programmed to gradually decrease the ambient temperature from $28^{\circ} \mathrm{C}$ to $16^{\circ} \mathrm{C}$ over approximately $80 \mathrm{~min}$.

Rectal temperature probes were inserted to a depth of $13 \mathrm{~cm}$ beyond the anal sphincter. Skin temperature sensors were attached with surgical tape to measurement sites on the forehead, abdomen, forearm, hand, thigh, leg, and foot. Measurements were made at intervals of $2 \mathrm{~s}$ using a data logger (LT-8A, Gram Corporation, Saitama, Japan). Mean skin temperature was calculated using the seven-point method of Hardy-DuBois [8]. $\mathrm{VO}_{2}$ and $\mathrm{VCO}_{2}$ were measured using a respiratory gas analyzer (AE-300S, Minato Medical Science, Osaka, Japan) in conjunction with a breathing tube, with a Rudolph mask used to measure expired gas (Rudolph mask, Nihon Kohden, Tokyo, Japan). To facilitate comparison with our previous studies and other studies, $\mathrm{VO}_{2}$ was divided by body mass, not fat-free mass. Electromyograms of the pectoralis major muscle were recorded by electromyograph (PolyTele, Nihon Santeku, Kyoto, Japan). Electromyogram data were recorded at a sampling frequency of $1,000 \mathrm{~Hz}$, and a bandpass filter (20 to $500 \mathrm{~Hz}$ ) was used in the analysis. Electromyographic data obtained during cold exposure were based on muscular changes during the first $10 \mathrm{~min}$ of thermoneutral baseline in $28^{\circ} \mathrm{C}$.

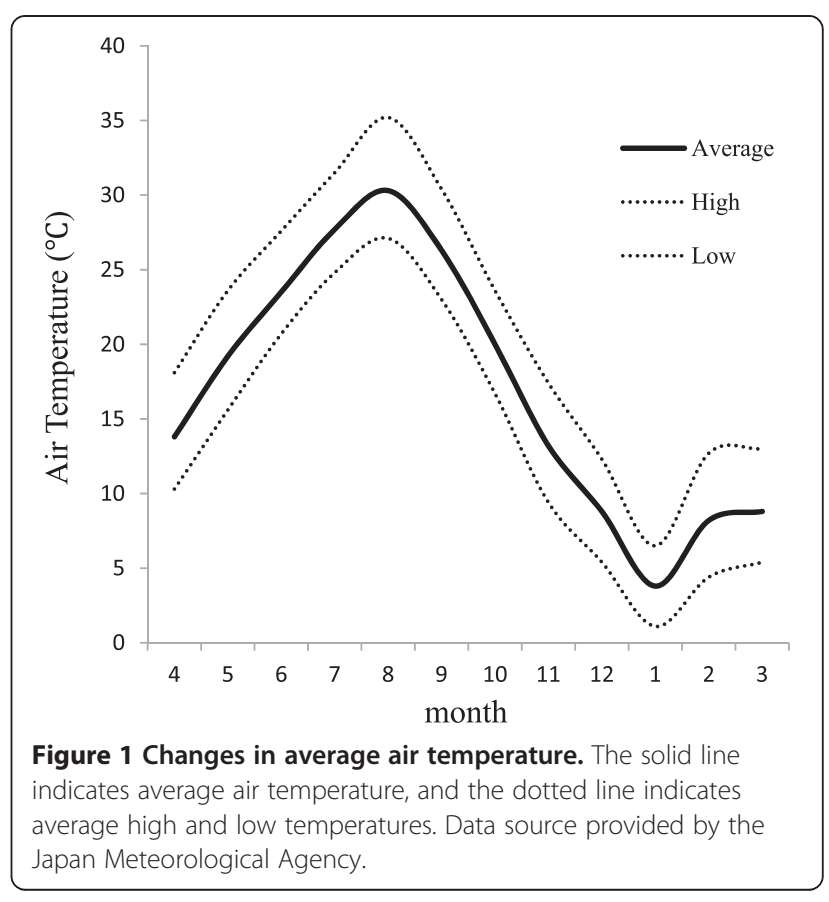

\section{Statistical analysis}

Morphological data were compared by the paired $t$ test. Physiological data were compared using two-way, repeatedmeasures, analysis of variance (ANOVA) (season and time), and Ryan's method was used for post hoc tests. The Pearson product-moment correlation analysis was used to determine the relation of $\triangle \mathrm{RER}$ to $\Delta \mathrm{VO}_{2}$. All data were expressed as the mean \pm standard error $(P<0.05)$.

\section{Results}

\section{Oxygen intake}

The effects of season $(F(1,16)=23.86, P<0.001)$ and time $(F(9,144)=15.54, P<0.001)$ were significant with respect to oxygen intake (Figure 2$)$. A significant interaction between season and time was also observed ( $F$ ( 9 , $144)=5.79, P<0.001)$. In a post hoc test conducted using winter data, $\mathrm{VO}_{2}$ tended to be greater during thermoneutral baseline conditions and was significantly greater in the period ranging from 30 to 100 min during cold exposure than it was during the same period in summer. In summer, $\mathrm{VO}_{2}$ was significantly lower during the first 30 min of cold exposure compared with the thermoneutral baseline and tended to be greater after $100 \mathrm{~min}$ of cold exposure than the thermoneutral baseline.

Table 1 Participants' morphological characteristics

\begin{tabular}{lccccc}
\hline & Height $(\mathbf{c m})$ & Body mass $(\mathbf{k g})$ & Body fat $(\%)$ & BMI & BSA $\left(\mathbf{m}^{\mathbf{2}}\right)$ \\
\hline Summer & $172.5 \pm 7.7$ & $59.3 \pm 7.2$ & $13.1 \pm 2.7$ & $19.9 \pm 2.0$ & $1.70 \pm 0.12$ \\
Winter & $172.6 \pm 7.5$ & $58.9 \pm 6.9$ & $12.6 \pm 1.8$ & $19.8 \pm 1.9$ & $1.70 \pm 0.11$ \\
\hline
\end{tabular}

No significant differences between the summer and winter values of participants' morphological characteristics were observed. All data are shown as mean \pm S.E. BMI, body mass index; BSA, body surface area. 


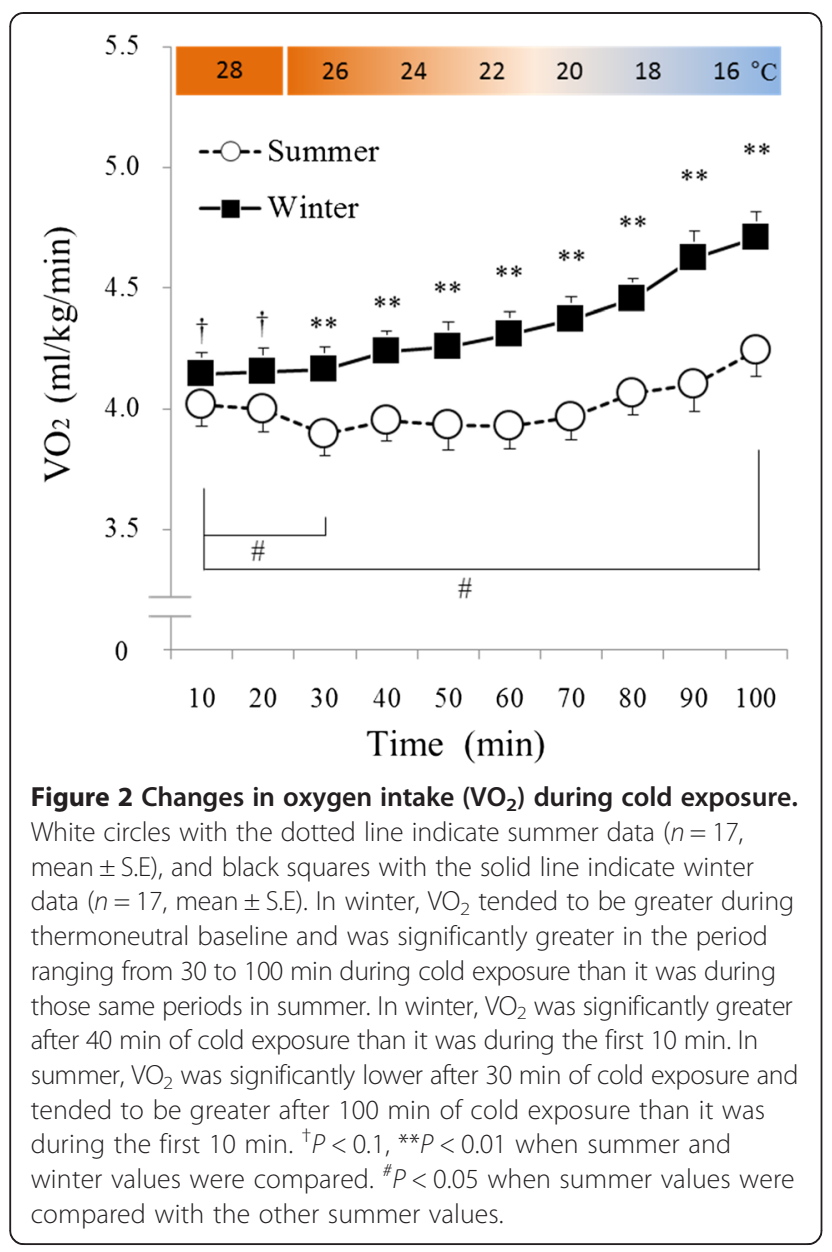

\section{Change in electromyogram}

The data are based on changes during the first $10 \mathrm{~min}$. There were no significant effects of season and time, and there was no significant interaction between season and time (Figure 3).

\section{Respiratory exchange ratio}

The effect of season $(F(1,16)=19.77, P<0.001)$ was significant with respect to RER (Figure 4). A significant interaction between season and time was also observed $(F(9,144)=3.47, P<0.001)$. In a post hoc test, RER was significantly lower over the course of the experiment in winter than it was in summer. In a post hoc test conducted using winter data, RER was significantly lower during periods of cold exposure.

\section{Correlation between $\triangle \mathrm{RER}$ and $\Delta \mathrm{VO}_{2}$ over the course of $100 \mathrm{~min}$ of cold exposure}

$\triangle \mathrm{RER}$ was 'subtract $10 \mathrm{~min}$ from $100 \mathrm{~min}$ ' data, and $\Delta \mathrm{VO}_{2}$ were calculated using 'ratio of $100 \mathrm{~min}$ from $10 \mathrm{~min}$ ' data (\%) (Figure 5). $\triangle \mathrm{RER}$ exhibited a significant negative relationship with $\Delta \mathrm{VO}_{2}$ in both summer $(r=-0.59, P<0.01)$ and winter $(r=-0.69, P<0.01)$.

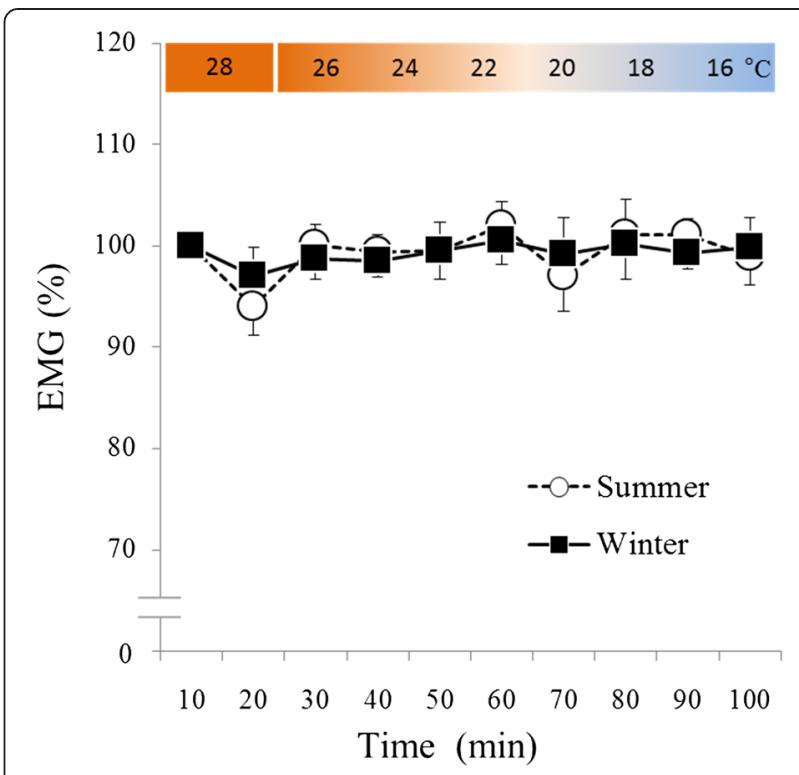

Figure 3 Change in electromyogram. White circles with the dotted line indicate summer data ( $n=17$, mean \pm S.E), and black squares with the solid line indicate the winter data $(n=17$, mean \pm S.E).

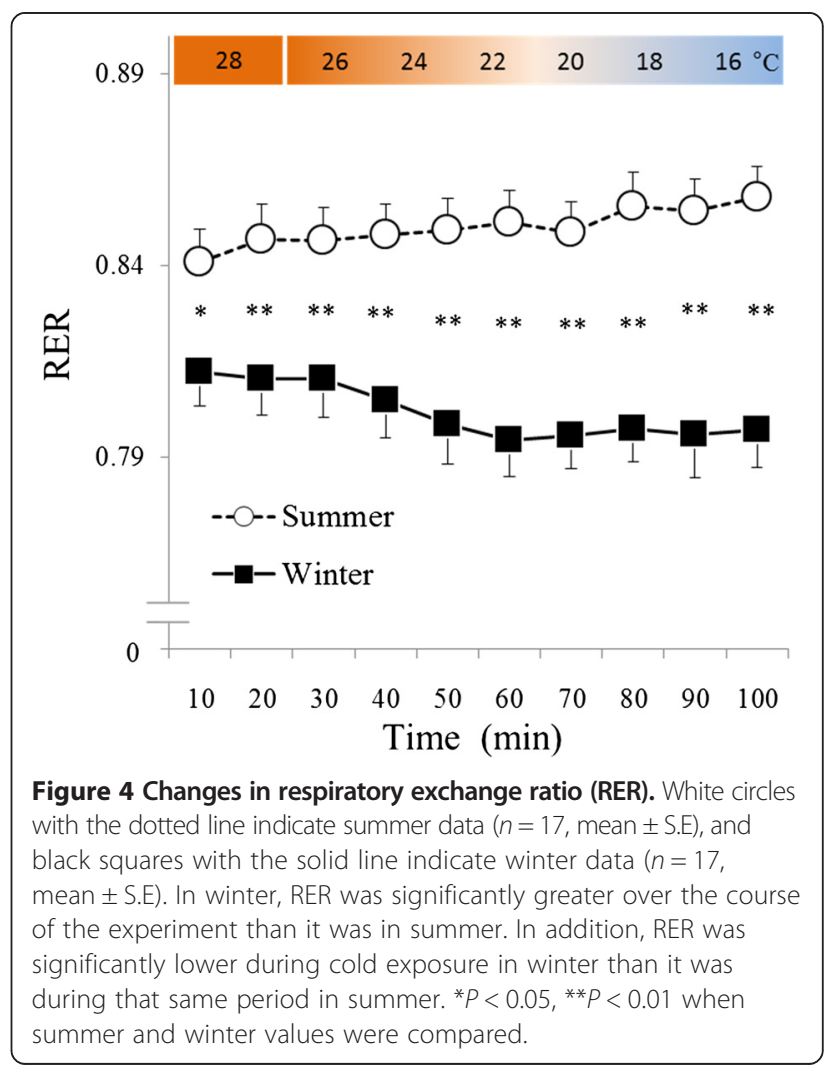




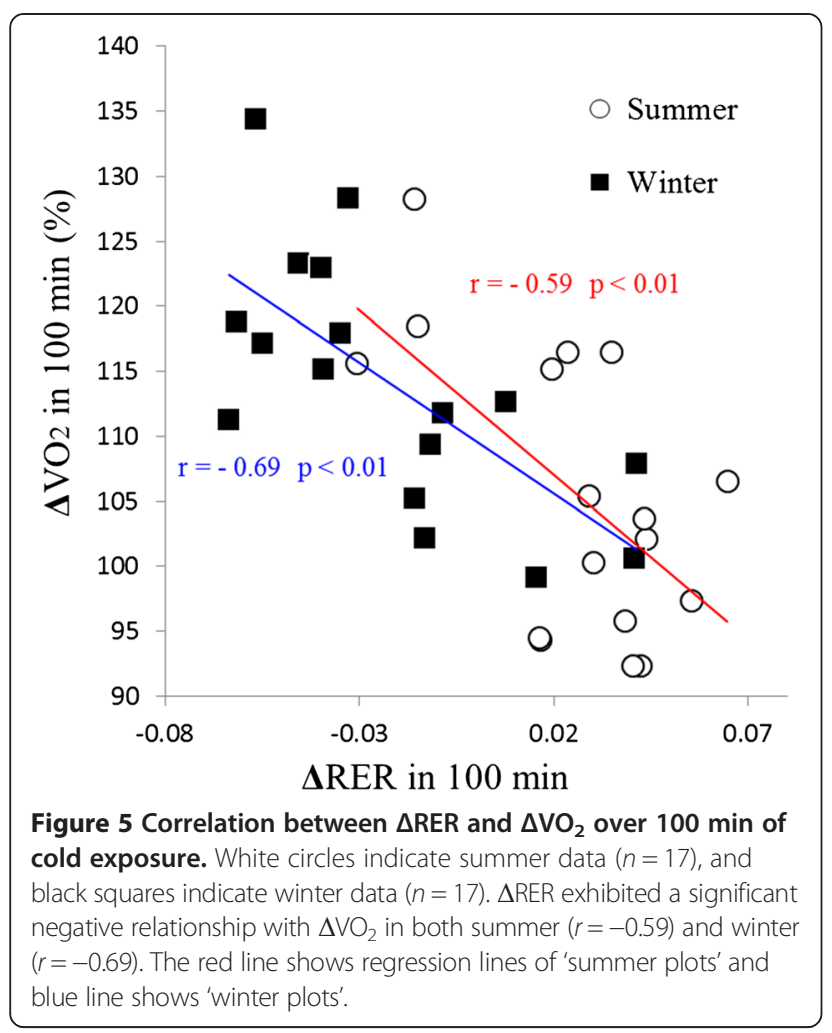

Individual differences of $\Delta \mathrm{VO}_{2}$ at $100 \mathrm{~min}$ in summer and winter

Most of the participants showed greater increase in $\mathrm{VO}_{2}$ in winter than in summer, but some showed no seasonal difference or a greater increase in summer than in winter (Figure 6).

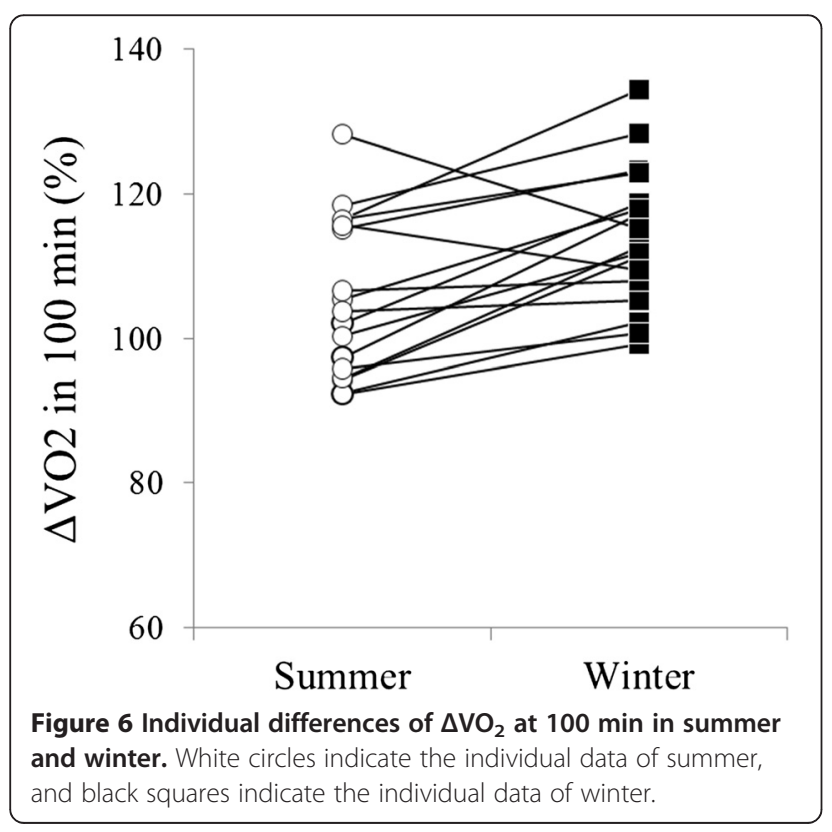

\section{Rectal temperature}

The effect of time $(F(9,144)=29.17, P<0.001)$ was significant with respect to $\mathrm{T}_{\mathrm{re}}$ (Figure 7 ). A significant interaction between season and time was also observed $(F(9,144)=2.45, P<0.05)$. In a post hoc test, $\mathrm{T}_{\mathrm{re}}$ tended to be lower in the period ranging from 40 to 70 min during cold exposure and was significantly lower in the period ranging from 50 to 60 min during cold exposure in winter than it was during the same period in summer. Furthermore, in winter, $\mathrm{T}_{\mathrm{re}}$ was significantly higher at $100 \mathrm{~min}$ than it was between 70 and 80 min during cold exposure.

\section{Distal skin temperatures}

The effects of season $(F(1,16)=6.49, P<0.05)$ and time $(F(9,144)=2325.09, P<0.001)$ were significant with respect to $\overline{\mathrm{T}}_{\text {dist }}$ (Figure 7 ). A significant interaction between season and time was also observed $(F(9,144)=31.41, P<$ 0.001). In a post hoc test, $\overline{\mathrm{T}}_{\text {dist }}$ was significantly lower in the period ranging from 10 to 50 min during cold exposure.

\section{Discussion}

In the present study, $\mathrm{VO}_{2}$ significantly and rapidly increased during winter (Figure 2) without shivering (Figure 3). In addition, RER was significantly lower during thermoneutral

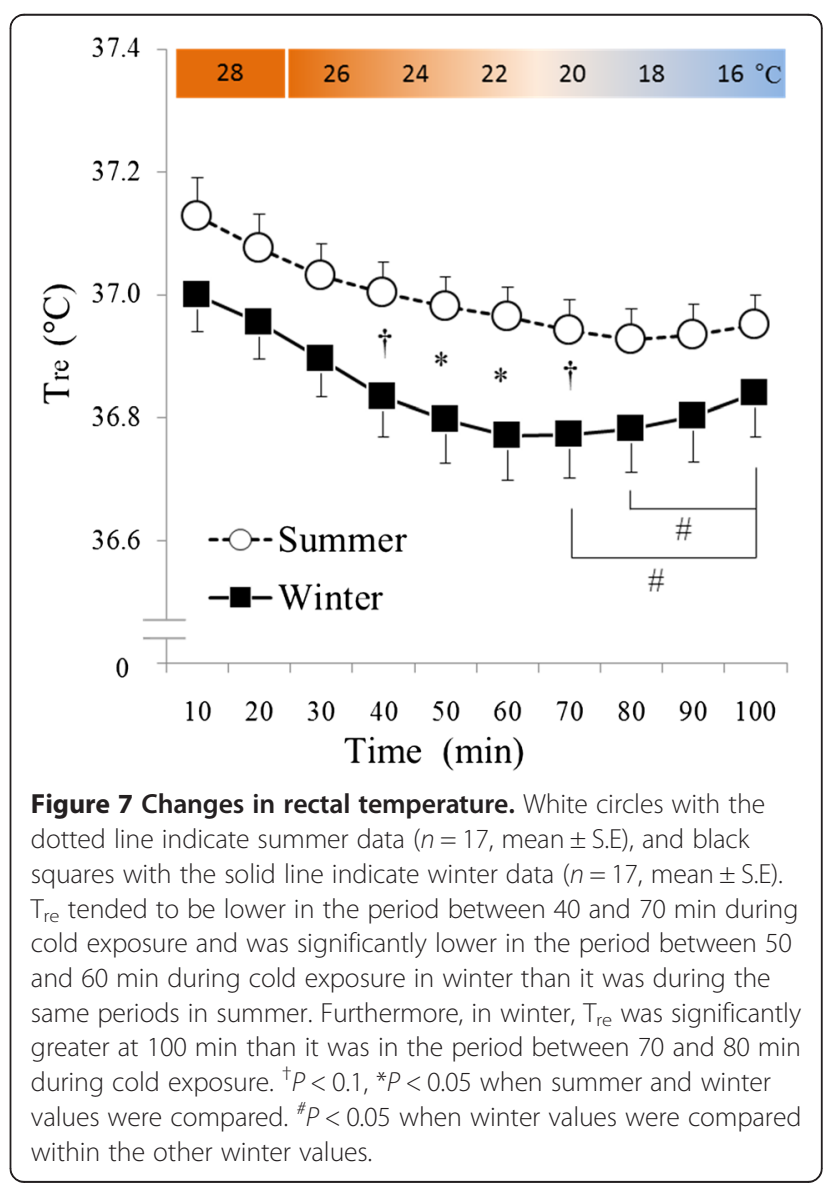


baseline conditions and periods of cold exposure in winter than in summer (Figure 4). However, in summer, $\mathrm{VO}_{2}$ was lowest at $30 \mathrm{~min}$ and highest at $100 \mathrm{~min}$ of cold exposure (Figure 2), and RER remained unchanged during cold exposure as compared to RER values recorded during thermoneutral baseline conditions (Figure 4). Although the heat source of NST remains unclear, brown adipose tissue (BAT) seems to account for the majority of heat generated by metabolizing free fatty acids $[9,10]$ in this way. Previous studies have demonstrated seasonal variation in BAT activity [11-13]; with the majority of individuals having exhibited greater BAT activity levels in winter than in summer, and a minority of individuals having exhibited increased BAT activity during both seasons [11]. Similarly, in the present study, the majority of the participants exhibited increases in $\mathrm{VO}_{2}$ ranging from $20 \%$ to $30 \%$ in winter (Figure 6), while a minority of participants also exhibited increased $\mathrm{VO}_{2}$ during summer. Some individuals did not exhibit increased $\mathrm{VO}_{2}$ in either season (Figure 6). In addition, a significant correlation was observed between $\triangle \mathrm{VO}_{2}$ and $\triangle \mathrm{RER}$ (Figure 5), which indicated that RER was low, because increased fat metabolism (decreased RER) would result in greater $\mathrm{VO}_{2}$ in winter. This finding indicates that an individual with increased NST $\left(\Delta \mathrm{VO}_{2}\right)$ might be metabolizing more fat via BAT (decreased $\triangle R E R$ ), which supports inter-individual differences in NST intensity. These results suggested that NST might be affected by seasonal acclimatization or individual differences in BAT activity.

Basal metabolic rate (BMR) is responsible for obligatory NST in humans and tends to be greater in winter than in summer $[14,15]$. However, recent studies have indicated that air conditioners are capable of eliminating seasonal variation in BMR [16]. However, although the present study did not measure $\mathrm{BMR}, \mathrm{VO}_{2}$ tended to be higher during thermoneutral conditions in winter than it did during the same periods in summer (Figure 2). In addition, some studies have reported NST generated from skeletal muscle $[17,18]$. Future studies should examine the relationship between NST of skeletal muscle and BMR in greater detail.

$\mathrm{T}_{\text {re }}$ was lower during periods of cold exposure in winter than it was during the same periods in summer (Figure 7). This result was similar to those of previous studies $[3,4]$. Previous studies have also reported that, to prevent heat loss, skin blood flow was reduced in winter [19], resulting in lower distal skin temperatures, as in the present study (Figure 8). These results indicated that significant vasoconstriction did occur, especially in the foot in winter. Based on the observations noted above, it was suggested that the prevention of heat loss due to vasoconstriction in the foot occurs in response to mild cold exposure in winter.

The limitations of the present study include the fact that it did not directly measure BAT activity. It is necessary to

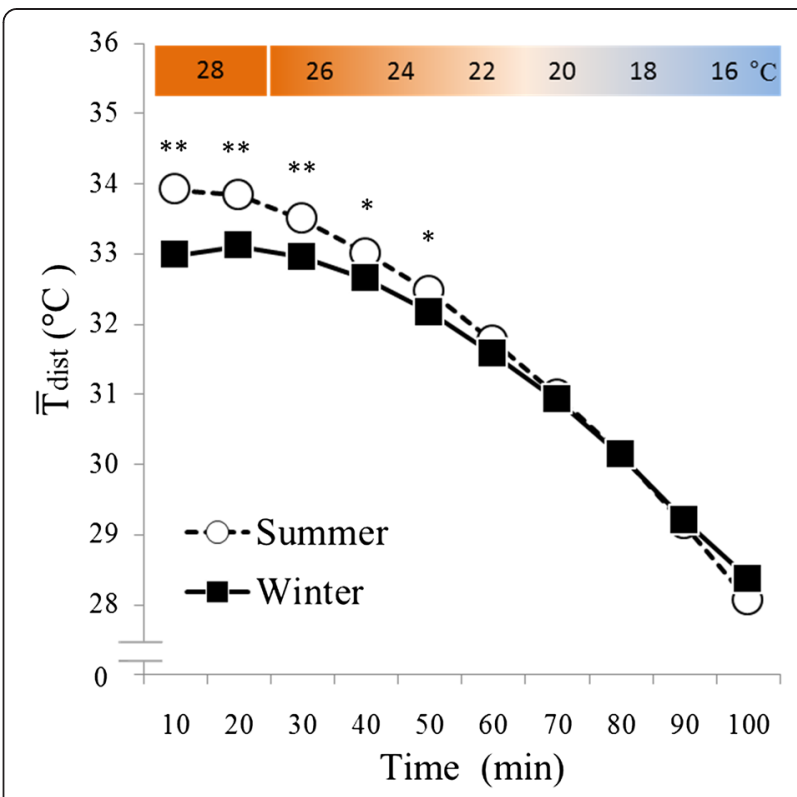

Figure $\mathbf{8}$ Changes in distal skin temperatures. White circles with a dotted line indicate summer data ( $n=17$, mean \pm S.E), and black squares with a solid line indicate winter data $\left(n=17\right.$, mean \pm S.E). ${ }^{*} P<$ $0.05,{ }^{*} P<0.01$ when summer and winter values were compared. In winter, $\overline{\mathrm{T}}_{\text {dist }}$ was significantly lower in the period between 10 and 50 min during cold exposure than it was during the same period in summer. ${ }^{*} P<0.05,{ }^{* *} P<0.01$ when summer and winter values were compared.

measure amounts of BAT by positron emission tomography. In addition, all participants in the study had normal BMI values. Physiological data should be obtained from subjects with BMI values above and below the normal range. Moreover, behavioral or eating habits need to be studied to achieve an understanding of individual variation, because such habits may influence physiological data. Although cessation of eating/drinking was almost the same in summer and winter, the time used $(2 \mathrm{~h})$ was not sufficient to constitute fasting. More detailed data on the effects of fasting time are needed. Future studies should also examine possible genetic factors contributing to individual differences in NST or BAT activity, such as gene polymorphisms [20-22], to better understand the nature of the population level and individual variation in the trait.

\section{Conclusion}

Increase of $\mathrm{VO}_{2}$ without shivering indicated an increase of NST, and a decrease of RER depends on the metabolization of fat in winter. These results suggested that NST activity was activated by seasonal acclimatization, and individual variation of NST depends on individual variation of fat metabolism. 


\section{Abbreviations}

BAT: Brown adipose tissue; BMI: Body mass index; BSA: Body surface area; NST: Non-shivering thermogenesis; RER: Respiratory exchange ratio;

ST: Shivering thermogenesis; $\mathrm{VCO}_{2}$ : Carbon dioxide output; $\mathrm{VO}_{2}$ : Oxygen intake.

\section{Competing interests}

The authors declare that they have no competing interests.

\section{Authors' contributions}

TN carried out the design of the present study and data analysis and drafted the manuscript. SW and KA contributed to the design of the experiments and checked the manuscript. MM, YE, and DC contributed to data collection and analysis. All authors read and approved the final manuscript.

\section{Acknowledgements}

This study was supported in part by JSPS KAKENHI (23247044, 26251050).

\section{Author details}

${ }^{1}$ Department of Public Health, Nagasaki University Graduate School of Biomedical Sciences, 1-12-4 Sakamoto, Nagasaki 852-8523, Japan. ${ }^{2}$ Department of Kansei Science, Graduate School of Integrated Frontier Sciences, Kyushu University, 4-9-1 Shiobaru, Minami-ku, Fukuoka 815-8540, Japan. ${ }^{3}$ Department of Human Science, Faculty of Design, Kyushu University, 4-9-1 Shiobaru, Minami-ku, Fukuoka 815-8540, Japan.

Received: 10 October 2014 Accepted: 19 February 2015

Published online: 13 March 2015

\section{References}

1. Adolph EF. General and specific characteristics of physiological adaptations. Am J Physiol. 1956;184:18-28.

2. Steegmann AT. Pearl memorial lecture human cold adaptation: an unfinished agenda. Am J Hum Biol. 2007;227:218-27.

3. Nishimura T, Motoi M, Niri Y, Hoshi Y, Kondo R, Watanuki S. Relationship between seasonal cold acclimatization and mtDNA haplogroup in Japanese. J Physiol Anthropol. 2012;31:22.

4. Mäkinen TM, Pääkkönen T, Palinkas LA, Rintamäki H, Leppäluoto J, Hassi J. Seasonal changes in thermal responses of urban residents to cold exposure. Comp Biochem Physiol A Mol Integr Physiol. 2004;139:229-38.

5. Vybíral S, Lesná I, Jansky L, Zeman V. Thermoregulation in winter swimmers and physiological significance of human catecholamine thermogenesis. Exp Physiol. 2000;85:321-6.

6. Kurazumi Y, Tsuchikawa T, Kakutani K, Torii T, Matsubara N, Horikoshi T. Evaluation of the conformability of the calculation formula for the body surface area of the human body. Jpn J Biometeorol. 2009;39:101-6.

7. Brozek J, Grande F, Anderson JT, Keys A. Densitometric analysis of body composition: revision of some quantitative assumptions. Ann N Y Acad Sci. 1963:110:113-40.

8. Hardy JD, DuBois EF. The technique of measuring radiation and convection. J Nutr. 1938:5:461-75.

9. van Marken Lichtenbelt WD, Vanhommerig JW, Smulders NM, Drossaerts $J M$, Kemerink GJ, Bouvy ND, et al. Cold-activated brown adipose tissue in healthy men. N Engl J Med. 2009;360:1500-8.

10. Yoneshiro T, Aita S, Matsushita M, Kameya T, Nakada K, Kawai Y, et al. Brown adipose tissue, whole-body energy expenditure, and thermogenesis in healthy adult men. Obesity (Silver Spring, Md). 2011;19:13-6.

11. Saito M, Okamatsu-Ogura Y, Matsushita M, Watanabe K, Yoneshiro T, Nio-Kobayashi J, et al. High incidence of metabolically active brown adipose tissue in healthy adult humans: effects of cold exposure and adiposity. Diabetes. 2009;58:1526-31.

12. Ouellet V, Routhier-Labadie A, Bellemare W, Lakhal-Chaieb L, Turcotte E, Carpentier AC, et al. Outdoor temperature, age, sex, body mass index, and diabetic status determine the prevalence, mass, and glucose-uptake activity of 18 F-FDG-detected BAT in humans. J Clin Endocrinol Metab. 2011:96:192-9.

13. van Marken Lichtenbelt WD, Schrauwen P. Implications of nonshivering thermogenesis for energy balance regulation in humans. Am J Physiol Regul Integr Comp Physiol. 2011;301:285-96.

14. Osiba S. The seasonal variation of basal metabolism and activity of thyroid gland in man. Jpn J Physiol. 1957;7:355-65.
15. Plasqui G, Kester ADM, Westerterp KR. Seasonal variation in sleeping metabolic rate, thyroid activity, and leptin. Am J Physiol Endocrinol Metab. 2003;285:338-43.

16. Maeda T, Hirota S, Ishibashi H, Okada Y, Yokoyama S, Kuramae M. Disappearance of seasonal variation in the basal metabolic rate in Japanese males. In: Abstract Book of the 10th International Congress of Physiological Anthropology. 2010.

17. Bal NC, Maurya SK, Sopariwala DH, Sahoo SK, Gupta SC, Shaikh SA, et al. Sarcolipin is a newly identified regulator of muscle-based thermogenesis in mammals. Nat Med. 2012;18:1575-9.

18. Astrup A, Bülow J, Madsen J, Christensen NJ. Contribution of BAT and skeletal muscle to thermogenesis induced by ephedrine in man. Am J Physiol. 1985;248:507-15.

19. van Ooijen MJ, van Marken Lichtenbelt WD, Van Steenhoven A, Westerterp KR. Seasonal changes in metabolic and temperature responses to cold air in humans. Physiol Behav. 2004;82:545-53.

20. Esterbauer H, Oberkofler H, Liu YM, Breban D, Hell E, Krempler F, et al. Uncoupling protein-1 mRNA expression in obese human subjects: the role of sequence variations at the uncoupling protein-1 gene locus. J Lipid Res. 1998;39:834-44.

21. Hancock AM, Clark VJ, Qian Y, Di Rienzo A. Population genetic analysis of the uncoupling proteins supports a role for UCP3 in human cold resistance. Mol BiolEvol. 2011;28:601-14.

22. Yoneshiro T, Ogawa T, Okamoto N, Matsushita M, Aita S, Kameya T, et al. Impact of UCP1 and B3AR gene polymorphisms on age-related changes in brown adipose tissue and adiposity in humans. Int J Obes (Lond). 2013;37:993-8.

\section{Submit your next manuscript to BioMed Central and take full advantage of:}

- Convenient online submission

- Thorough peer review

- No space constraints or color figure charges

- Immediate publication on acceptance

- Inclusion in PubMed, CAS, Scopus and Google Scholar

- Research which is freely available for redistribution 